\title{
ASSESSMENT OF LOW-COST PARTICULATE MATTER SENSORS
}

\author{
K. Lehmann ${ }^{1 *}$, A. Minhans ${ }^{1}$, M. K. Fajari ${ }^{1}$, M. Hahn ${ }^{1}$ \\ ${ }^{1}$ Dept. of Photogrammetry and Geoinformatics, Hochschule für Technik Stuttgart, Germany - (82leka1mpg, 72mian1mpg, \\ 82fama1mpg, michael.hahn)@hft-stuttgart.de
}

Commission IV, WG IV/3

KEY WORDS: Particulate Matter, Low-cost Sensors, PM 2.5, PM 10.0, Meteorological Parameters, Air Quality, Landesanstalt für Umwelt Baden-Württemberg

\begin{abstract}
:
The effect of particulate matter is increasingly gaining significance due to its harmful effects on human and urban ecosystems. In view of it, many communities worldwide are collecting air quality data privately to influence their policy makers to make stricter provisions for reducing harmful emissions and thereby improving their quality of life. Likewise, in many German cities, a community of air quality monitors which rely on low-cost PM Sensors is gathering momentum. Such communities possess privately-owned \& low-cost air quality monitoring devices that claim to accurately measure PM concentrations and are openly accessible via internet. One such initiative is an air quality monitoring network viz. "luftdaten.info", which contains of more than 300 low-cost sensors that consistently obtains PM data, colloquially referred as fine dust, in the city of Stuttgart as well as its surrounding districts. Besides, eight stations are continuously monitoring PM concentration in Stuttgart; these are operated by the State Environmental Agency (LuBWLandesanstalt für Umwelt Baden-Württemberg). Stuttgart University of Applied Sciences (HFT) has currently installed 7 low-cost PM sensors to monitor and study PM concentration in one of its projects. This study endeavors to relate PM 2.5 and PM 10.0 using lowcost sensors. It intends to investigate the reliability of the measured PM concentration using such low-costs sensors once these are placed horizontally and vertically apart and comparing the measures of the 7 sensors. Another objective is to compare the PM concentration measurements with a meteorological station operated by the State of Baden-Wuerttemberg in the vicinity. A correlation analysis is performed to develop understanding of relationships of PM concentration with meteorological parameters, viz. with respect to ambient temperature, air pressure, humidity, wind speed and wind direction. Furthermore, it attempts to develop a regression model using above listed meteorological parameters. Finally, deficiencies in the measurement of low-costs and its placement effects are commented. Further suggestions are made for improving the data capturing and analytical procedures while using low-cost sensors..
\end{abstract}

\section{INTRODUCTION}

\subsection{General}

Fine dust consists of a complex mixture of solid and liquid particles and is divided into different fractions depending on their size. A distinction is made between PM 10 (PM, particulate matter) with a maximum diameter of 10 micrometers $(\mu \mathrm{m}), \mathrm{PM}$ 2.5 and ultrafine particles with a diameter of less than $0.1 \mu \mathrm{m}$. Particulate matter is primarily generated by human actions: primary particulate matter is produced by emissions from motor vehicles, power plants and district heating plants, stoves and heaters in residential buildings, during metal and steel production or when handling bulk materials. But it can also be of natural origin (for example, because of soil erosion). In metropolitan areas, road traffic is the dominant source of dust. In the process, particulate matter is released not only from engines - primarily from diesel engines - but also from brake and tire abrasion and from the whirling up of dust from the road surface. Another big source of PM is agriculture: the emissions of gaseous precursors, in particular ammonia emissions from animal husbandry, contribute to the formation of secondary fine dust.

PM 10 can penetrate through the nasal cavity in humans, PM 2.5 into the bronchi and alveoli and ultrafine particles into the lung tissue and even into the bloodstream. Depending on the size and penetration depth of the particles, the health effects of particulate matter are different. They range from mucosal irritation, local inflammation in the trachea and bronchi or the pulmonary alveoli to increased plaque formation in the blood vessels, thrombosis or changes in the regulatory function of the autonomic nervous system (heart rate variability).

For the protection of human health, since January 1, 2005, limit values for the particulate matter fraction PM 10 have been valid throughout Europe. The daily limit value is $50 \mu \mathrm{g} / \mathrm{m} 3$ and it must not be exceeded more than 35 times a year. The permissible annual mean value is $40 \mu \mathrm{g} / \mathrm{m} 3$. Since 2008, a target value of 25 $\mu \mathrm{g} / \mathrm{m} 3$ annual average has been applicable across Europe for the even smaller particles PM 2.5Since January 1, 2015, this value must be adhered to.

In the City of Stuttgart, more than 300 low-cost sensors to collect PM data are already running. The Stuttgart University of Applied Sciences (HFT) currently measures PM using 7 low cost sensors. The accuracy of these sensors in measuring PM 10 and PM 2.5 will be investigated in this study.

For this study the primary aim is to assess the quality of low-cost PM sensors. The low-cost PM sensor measurements will be compared and analyzed according to the accuracy of vertical and horizontal placement of sensors. In another objective, the measurements of the low-cost sensors are compared with the state-owned meteorological sensor in the vicinity (located in Bad Cannstatt).

\subsection{Set up of the instrument}

The PM particles flow through the sampling inlet and enter the sensing chamber, where the incident laser beam is scattered depending on their size. A low noise amplifier operates as a transducer, by transforming the collected light to various signal 
intensities. The SDS011 sensor used for this investigation measures PM 2.5 and PM 10 within the range 0.0 to $999.9 \mu \mathrm{g} / \mathrm{m} 3$.

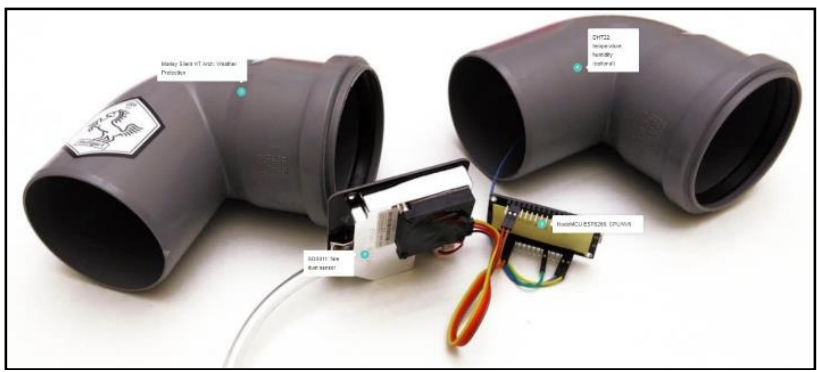

Figure 1. A typical low cost sensor used in the study (https://luftdaten.info)

\section{METHODOLOGY}

\subsection{Study Methodology}

Six sensors were set up alongside at the façade of HFT Building 2. They were placed in different heights and with horizontal spacing to derive the spatial-temporal relationships between the sensors. This evaluation was done regarding different criteria, viz distance, height, times of the day/week/years among other criteria. For the evaluation of the data, correlation with the meteorological parameters with significance testing were processed. The selection of the sensors, time of experiment, daily measurements, weekly measurement and day peaks were done after checking the consistency of the data for examination.

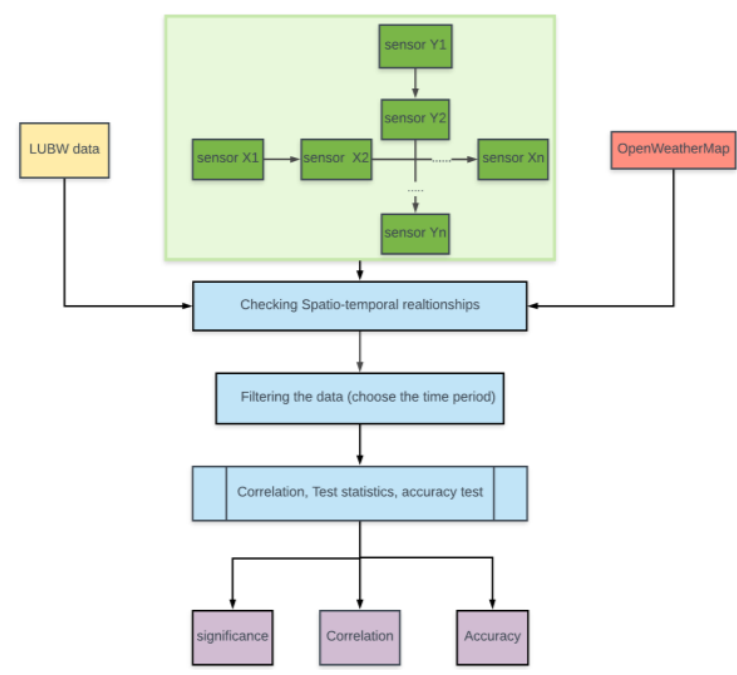

Figure 2. Flowchart of the experiment

The experiments are divided into 3 measurements and the data comes from 3 different periods of time. The first period is the data of only low-const sensors comparing the air quality measurement in different horizontal positions and different heights. The data was measured in the period of April 22nd, 2019 to May 4th, 2019. The second period of our data is the measurements data of 5 low cost sensors in Building 2 HFT Stuttgart that start in June 1st, 2019 and finish at June 5th, 2019. In this period, the weather data were included viz. data of temperature, humidity, pressure, wind speed and wind direction. The weather data comes from OpenWeatherMap API. The last data measurement is conducted in June 7th, 2019at the location of the LUBW high accuracy sensor in Stuttgart-Bad Cannstatt.
This is not a full 24 hours measurement, PM 2.5 and PM 10 were only measured for a 9 hours duration starting at 12.30 and finishing at 20.30 .

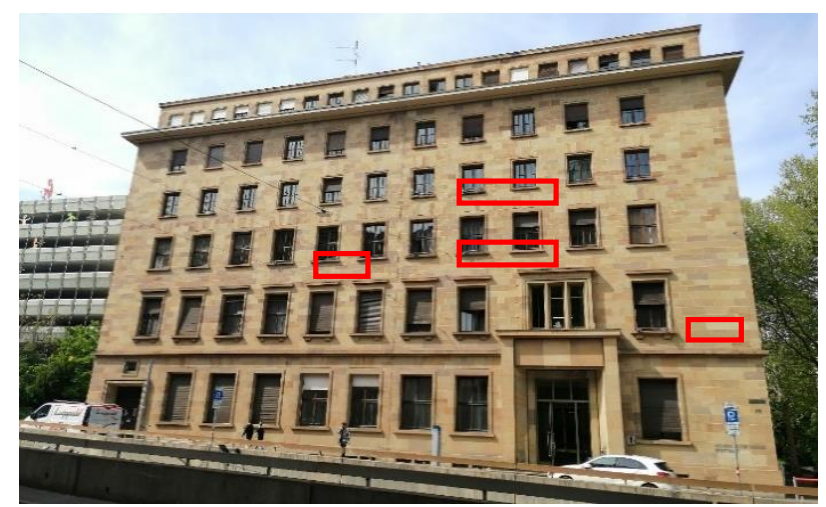

Figure 3. Location of experiment: HfT Stuttgart Building 2

\subsection{Experiment}

2.2.1 PM comparison with respect to different height and different horizontal distance

PM comparison with respect to different heights (vertical placement) and different horizontal distances (horizontal placement) were conducted. This experiment assumed that there will not be significant differences between the horizontal and vertical placement of the PM concentration. In the first condition, 3 different PM sensors in 3 different floors of Building 2 were placed. Every floor has about 3 meters difference in height. In the second condition, other sensors which were placed in the same floor but at different horizontal placements were evaluated. All the test sensors were placed towards the south side of HfT Stuttgart Building 2 facing Schloßstraße.

In the comparison process, we apply the statistical test of a mean value of normal distribution. In the experiment, the variance $\sigma^{2}$ in unknown, so we use $\mathrm{s}^{2}$ as estimation for $\sigma^{2}$. It is possible to use one sided test or two sided test (one or two tail test). The procedure to run this test for one sided test is following the scheme below:

- $\quad$ Set up the null hypothesis $\left(\mathrm{H}_{0}\right): \mu=\mu_{0}$, and define the level of significance $(\alpha)=5 \%$.

- $\quad$ Set up the alternative hypothesis $\left(\mathrm{H}_{\mathrm{A}}\right): \mu>\mu_{0}$.

- Calculate test statistic for set of observations:

$$
\begin{aligned}
& T=\frac{x-\mu 0}{s x} \\
& s x=\frac{s}{\sqrt{n}}
\end{aligned}
$$

- Define the test limits $\mathrm{t}_{1-\alpha ; n-1}$ out of the table of t-distribution for acceptance or rejection of $\mathrm{H}_{0}$ out of the distribution of the test. Calculate critical value (k) to decide the test:

$$
\mathrm{k}=\mu_{0}+\mathrm{t}_{1-\alpha: \mathrm{n}-1} * s x
$$

- Test decision.

Acceptance of $\mathrm{H}_{0}$ for $\mathrm{T} \leq \mathrm{t}_{1-\alpha ; \mathrm{n}-1}$ respectively $\mathrm{x} \leq \mathrm{k}$ Rejection of $\mathrm{H}_{0}$ for $\mathrm{T}>\mathrm{t}_{1-\alpha ; \mathrm{n}-1}$ respectively $\mathrm{x}>\mathrm{k}$ 
a. Horizontal test

The PM concentration data for 13 days or almost two weeks period (April 22 $2^{\text {nd }}, 2019$ - May $4^{\text {th }}, 2019$ ) were analysed. In this period of time, PM concentration on weekdays and weekend were measured to establish the pattern and trend of PM concentration in both weekdays and weekend. The figure 4 shows the scatter plot of PM 2.5 and PM 10 measurements for 1 week. In this period of examination, on Tuesday, April 30th, showed the highest value in both PM 2.5 and PM 10 concentration. It is observed to be increasing during midnight, with the maximum more than $25 \mu \mathrm{g} / \mathrm{m} 3$ for PM 2.5 and more than $50 \mu \mathrm{g} / \mathrm{m} 3$ for PM 10 value. This exceeds the daily average as per the daily standard value obtained from World Health Organisation (WHO).

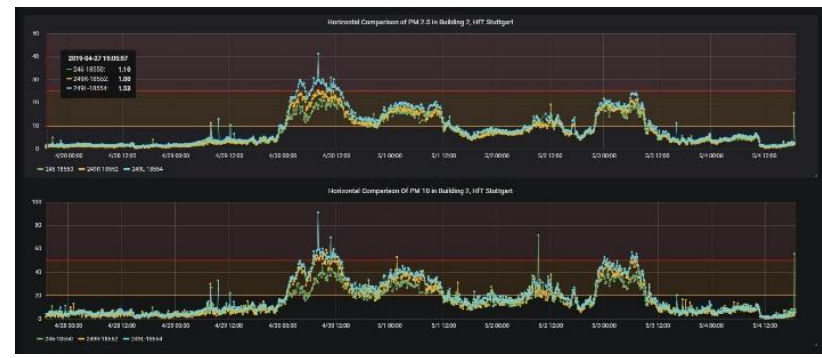

Figure 3. PM data profile for different horizontal placement of sensors

Furthermore, the significance level of 3 measurements by comparing the mean value of hourly data were estimated. A 95\% confidence level to decide the differences in the results is used. Among the three measurements from 3 different sensors horizontally placed the PM values were not found to be significantly different. Therefore, it could be assumed that the PM values from these 3 different sensors were similar. In other words, horizontal placement alongside of a road did not affect the air quality in terms of only PM concentration.

\begin{tabular}{|c|c|c|c|}
\hline $\begin{array}{c}\text { Horizontal } \\
\text { distance }\end{array}$ & \multicolumn{3}{|c|}{ Result } \\
\hline $6 \mathrm{~m}$ & PM $10 \leq \mathrm{k}$ & PM $2.5 \leq \mathrm{k}$ & $\begin{array}{c}\text { Not } \\
\text { significant } \\
\text { different }\end{array}$ \\
\hline $8 \mathrm{~m}$ & PM 10 $\leq \mathrm{k}$ & PM $2.5 \leq \mathrm{k}$ & $\begin{array}{c}\text { Not } \\
\text { significant } \\
\text { different }\end{array}$ \\
\hline $2 \mathrm{~m}$ & PM 10 $\leq \mathrm{k}$ & PM $2.5 \leq \mathrm{k}$ & $\begin{array}{c}\text { Not } \\
\text { significant } \\
\text { different }\end{array}$ \\
\hline
\end{tabular}

Table 1. Statistical test for sensors in different horizontal distance

b. Vertical test

Likewise with the first condition above, same location in Building 2 were used to place 3 different sensors in 3 different floors (vertical placement). The first sensor was installed in the first floor. The other two were installed in the second floor and in the third floor. The measurements were taken from the same period of time as with the first condition. A total of 13 days of measurements data were used, starting on April $22^{\text {nd }}, 2019$ and ending on May $4^{\text {th }}$, 2019.

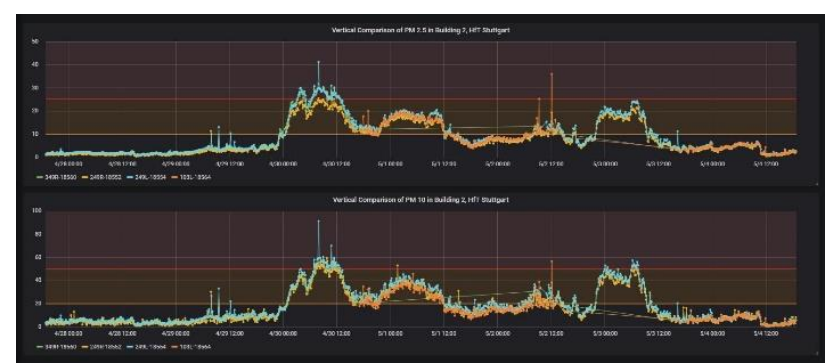

Figure 4. PM data profile for different vertical placement of sensors

The PM data were compared for hourly averages of PM concentration in case of 3 different sensors placed vertically. Three comparisons were made based on 3 combination data sets. Due to constraints within experimental setup, limited datasets were used. Although limited datasets were used, similar statistical tests were conducted for the second condition as well. The statistical tests used $95 \%$ confidence level to calculate the critical value $(\mathrm{k})$ to decide whether the observations were significantly different or not. The statistical results showed that by placing the sensor in different heights (up to 6 meters), give the similar PM concentration measurements, for both PM 2.5 and PM 10 sensors.

\begin{tabular}{|c|c|c|c|c|}
\hline $\begin{array}{c}\text { Height } \\
\text { difference }\end{array}$ & $\begin{array}{c}\text { Data } \\
\text { (days) }\end{array}$ & \multicolumn{3}{|c|}{ Result } \\
\hline $\begin{array}{c}3 \mathrm{~m} \\
\left(1^{\text {st }}-2^{\text {nd }}\right. \\
\text { Floor })\end{array}$ & 5 & PM $10 \leq \mathrm{k}$ & PM 2.5 $\leq \mathrm{k}$ & $\begin{array}{c}\text { not } \\
\text { significant } \\
\text { different }\end{array}$ \\
\hline $\begin{array}{c}3 \mathrm{~m} \\
\left(2^{\text {nd }}-3^{\text {rd }}\right. \\
\text { Floor })\end{array}$ & 10 & PM $10 \leq \mathrm{k}$ & PM $2.5 \leq \mathrm{k}$ & $\begin{array}{c}\text { not } \\
\text { significant } \\
\text { different }\end{array}$ \\
\hline $\begin{array}{c}6 \mathrm{~m} \\
\left(1^{\text {st }}-3^{\text {rd }}\right. \\
\text { Floor })\end{array}$ & 3 & PM $10 \leq \mathrm{k}$ & PM 2.5 $\leq \mathrm{k}$ & $\begin{array}{c}\text { not } \\
\text { significant } \\
\text { different }\end{array}$ \\
\hline
\end{tabular}

Due to obtained results of the statistical tests for both conditions (2.2.1.a and 2.2.1.b), the sensors were assumed to be therefore correlated. However, further research should be conducted to verify the correlation of PM measurements at larger horizontal and vertical placements.

\subsubsection{Low-Cost PM Sensor Absolute Quality}

To analyse the quality of our low-cost PM sensor, we bring our sensor and place it in the LUBW sensor site in Bad Cannstatt. The complete address is Gnesener Straße (Seubertstraße 1). The LUBW PM is installed at 3,9 meters above ground surface. Beside PM sensor, there are another sensor that measure Nitrogen dioxide (NO2) and Ozone (O3). For the comparison, this experiment only focus in the PM measurements. 
Placing in the same location as the high quality sensor is the way to assume the low-cost PM sensor measure the same air condition. In the experiment 2.2.1.b shows that the height different less than 6 meters is not significant factor and give the similar PM value. Base on this result, the placement of low cost sensor side by side with the LUBW sensor is not necessary. The low cost sensor take place in front of the fence of LUBW sensor site or it is about 3 meters away from the LUBW sensor. The height is around 1,5 meter above the ground. The measurement starts at 12.30 and end at 20.20 in the evening. It is almost 9 hours measurement. The low-cost sensor use sensor number 18564. It uses mobile connection to send and stream the measurement data, so user can monitor through the sensor network. In the other hand, the access of LUBW air quality data are limited. The only data that can be accessed and used is the visualization of hourly PM measurements of LUBW sensor. This data is published real time in the LUBW website in the diagram format. The diagram show integer value in hourly period of time. Due to the limitation in accessing the data from high accuracy sensors, the adjustment needed in order to get same period of data and same number of measurements. The adjustment is performed by calculating the hourly average value of PM data from sensor 18564. And in the end, it can match with LUBW data.

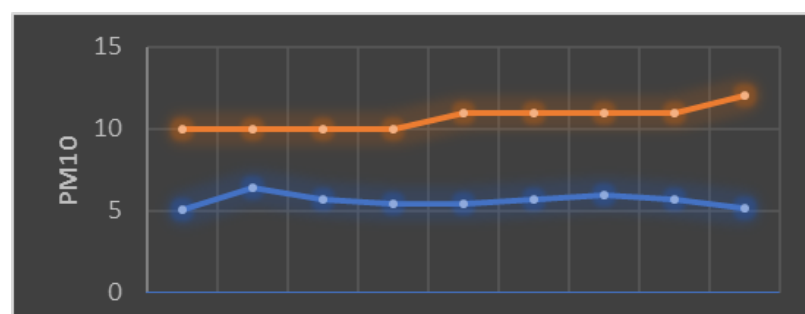

12:00 13:00 14:00 15:00 16:00 17:00 18:00 19:00 20:00 Time
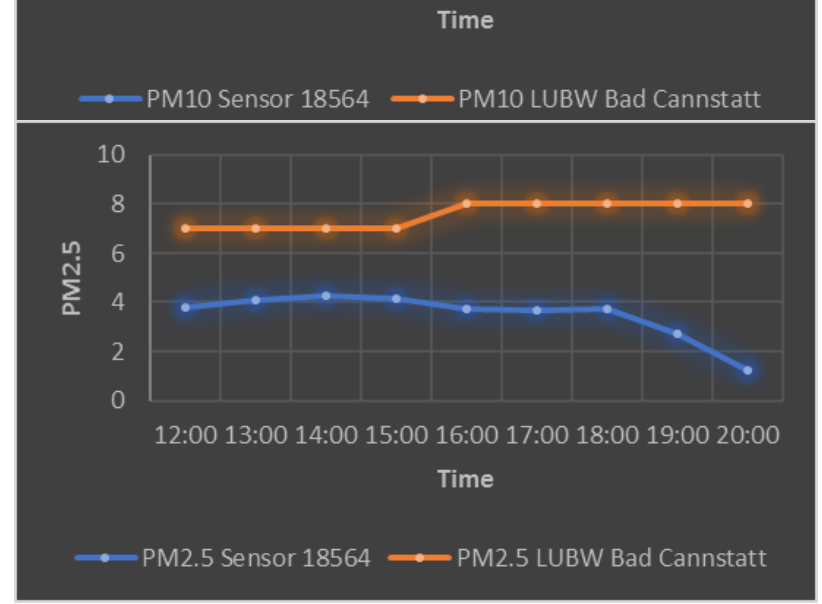

Figure 6. PM data Comparison

The chart in the figure 6 show the PM comparison between LUBW sensor and the low-cost one. Both PM 10 and PM 2.5, the LUBW measurements are higher than the low-cost measurements. The residual are vary from $2.75 \mu \mathrm{g} / \mathrm{m}^{3}$ to 6.88 $\mu \mathrm{g} / \mathrm{m}^{3}$. The trend line of LUBW PM data are rising. On the contrary, PM 2.5 value of sensor 18564 is decrease and reach the lowest at $1.21 \mu \mathrm{g} / \mathrm{m}^{3}$. This is happened in the end of the measurement at 20.00. In this time, both PM 2.5 residual and PM 10 residual are in the maximum value.

The number of measurements for the comparison dataset are only 9 measurements data. Originally the low-cost PM data record 48 measurements. It records PM value every 10 minutes. But it need to be compressed into hourly average. From these all measurements, we can calculate the variance and the standard deviation as the parameters of quality PM sensor. In this absolute comparison, the PM value of LUBW sensor are assigned as the true value. Then following by calculating all residuals for both PM 2.5 and PM 10. After that, the residuals value is used as an input value to get variance and standard deviation. Both PM 10 and PM 2.5 value are below the value of high accuracy PM sensor. The standard deviation for PM 10 measurement is 5.136 $\mu \mathrm{g} / \mathrm{m}^{3}$. The accuracy of PM 2.5 is slightly higher than PM 10. It get $4.269 \mu \mathrm{g} / \mathrm{m}^{3}$. The summary of accuracy calculation can be seen in the table 1 below.

\begin{tabular}{|c|c|c|c|}
\hline $\begin{array}{c}\text { Particulate } \\
\text { Matter }\end{array}$ & RMSE & $\begin{array}{c}\text { max } \\
\text { residual }\end{array}$ & $\begin{array}{c}\text { min } \\
\text { residual }\end{array}$ \\
\hline PM 10 & 5.136 & 6.88 & 3.6 \\
\hline PM 2.5 & 4.269 & 6.79 & 2.75 \\
\hline
\end{tabular}

Table 3. RMSE and residual value of low-cost PM sensor

\subsubsection{Correlation}

Correlation was conducted to establish the extent of relationship between the chosen variables: (i) Particulate matter (PM 10), (ii) Particulate matter (PM 2.5), (iii) Temperature, (iv) Humidity, (v) Atmospheric Pressure, (vi) Wind speed and (vii) Wind direction. The extent of relationship between variables is given by range from +1 (perfect positive correlation) and -1 (perfect negative correction), with 0 signifying no correction between two variables.

Although, several methods are available to study correlation, Karl Pearson coefficient of correlation, also known as product moment coefficient of correlation was used to establish correlation.

$$
\boldsymbol{r}=\frac{\mathbf{n}\left(\sum \mathbf{x y}\right)-\left(\sum \mathbf{x}\right)\left(\sum \mathbf{y}\right)}{\sqrt{\left[\boldsymbol{n}\left(\sum \mathbf{x}^{2}\right)-\left(\sum \mathbf{x}\right)^{2}\right]\left[n\left(\sum \mathbf{y}^{2}\right)-\left(\sum \mathbf{y}\right)^{2}\right]}}
$$

where:

$\mathrm{n}=$ number of pair of variables

$\Sigma \mathrm{x}=$ sum of $\mathrm{x}$ variables

$\Sigma \times 2=$ square of $\mathrm{x}$ variables

$\Sigma \mathrm{y}=$ sum of $\mathrm{y}$ variables

$\Sigma$ y2 $=$ square of y variables

$\Sigma \mathrm{xy}=$ sum of product of $\mathrm{x}$ and $\mathrm{y}$ variables

The correlation coefficients are given in the Table 4. 


\begin{tabular}{|c|c|c|c|c|}
\hline & $\begin{array}{l}\text { Sensor } \\
\text { Num. }\end{array}$ & PM & Temp. & Humidity \\
\hline \multirow{10}{*}{ 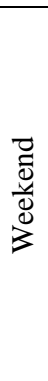 } & \multirow[t]{2}{*}{18550} & PM 10 & -0.691 & 0.615 \\
\hline & & PM 2.5 & -0.664 & 0.596 \\
\hline & \multirow[t]{2}{*}{18552} & PM 10 & -0.713 & 0.636 \\
\hline & & PM 2.5 & -0.705 & 0.646 \\
\hline & \multirow[t]{2}{*}{18554} & PM 10 & -0.726 & 0.669 \\
\hline & & PM 2.5 & -0.728 & 0.674 \\
\hline & \multirow[t]{2}{*}{18560} & PM 10 & -0.725 & 0.660 \\
\hline & & PM 2.5 & -0.757 & 0.698 \\
\hline & \multirow[t]{2}{*}{18564} & PM 10 & -0.769 & 0.719 \\
\hline & & PM 2.5 & -0.769 & 0.725 \\
\hline \multirow{10}{*}{ 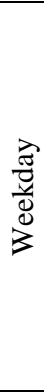 } & \multirow[t]{2}{*}{18550} & PM 10 & -0.226 & 0.275 \\
\hline & & PM 2.5 & -0.513 & 0.585 \\
\hline & \multirow[t]{2}{*}{18552} & PM 10 & -0.207 & 0.267 \\
\hline & & PM 2.5 & -0.275 & 0.366 \\
\hline & \multirow[t]{2}{*}{18554} & PM 10 & -0.415 & 0.475 \\
\hline & & PM 2.5 & -0.635 & 0.712 \\
\hline & \multirow[t]{2}{*}{18560} & PM 10 & -0.446 & 0.546 \\
\hline & & PM 2.5 & -0.615 & 0.723 \\
\hline & \multirow[t]{2}{*}{18564} & PM 10 & -0.001 & 0.190 \\
\hline & & PM 2.5 & -0.218 & 0.446 \\
\hline & \multirow[t]{2}{*}{ verall } & PM 10 & -0.539 & 0.539 \\
\hline & & PM 2.5 & -0.675 & 0.651 \\
\hline
\end{tabular}

\begin{tabular}{|c|c|c|c|c|c|}
\hline & $\begin{array}{c}\text { Sensor } \\
\text { Num. }\end{array}$ & PM & Press. & $\begin{array}{l}\text { Wind } \\
\text { Speed }\end{array}$ & $\begin{array}{c}\text { Wind } \\
\text { Direction }\end{array}$ \\
\hline \multirow{10}{*}{$\begin{array}{l}\overrightarrow{0} \\
\frac{\vec{v}}{0} \\
\overrightarrow{0} \\
3\end{array}$} & \multirow[t]{2}{*}{18550} & PM 10 & 0.239 & -0.556 & 0.663 \\
\hline & & PM 2.5 & 0.197 & -0.531 & 0.706 \\
\hline & \multirow[t]{2}{*}{18552} & PM 10 & 0.267 & -0.548 & 0.644 \\
\hline & & PM 2.5 & 0.237 & -0.549 & 0.707 \\
\hline & \multirow[t]{2}{*}{18554} & PM 10 & 0.266 & -0.580 & 0.677 \\
\hline & & PM 2.5 & 0.227 & $\begin{array}{l}-0.570 \\
\end{array}$ & 0.746 \\
\hline & \multirow[t]{2}{*}{18560} & PM 10 & 0.265 & -0.572 & 0.694 \\
\hline & & PM 2.5 & 0.255 & -0.586 & 0.748 \\
\hline & \multirow[t]{2}{*}{18564} & PM 10 & 0.320 & -0.613 & 0.669 \\
\hline & & PM 2.5 & 0.289 & -0.605 & 0.729 \\
\hline \multirow{10}{*}{ 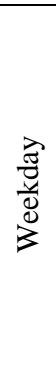 } & \multirow[t]{2}{*}{18550} & PM 10 & 0.041 & -0.188 & 0.078 \\
\hline & & PM 2.5 & -0.146 & -0.360 & -0.004 \\
\hline & \multirow[t]{2}{*}{18552} & PM 10 & 0.031 & $\begin{array}{c}-0.069 \\
\end{array}$ & 0.025 \\
\hline & & PM 2.5 & -0.196 & -0.141 & -0.014 \\
\hline & \multirow[t]{2}{*}{18554} & PM 10 & 0.164 & -0.255 & 0.076 \\
\hline & & PM 2.5 & 0.005 & $\begin{array}{c}-0.419 \\
\end{array}$ & 0.029 \\
\hline & \multirow[t]{2}{*}{18560} & PM 10 & 0.177 & -0.283 & 0.086 \\
\hline & & PM 2.5 & -0.003 & -0.384 & 0.065 \\
\hline & \multirow[t]{2}{*}{18564} & PM 10 & -0.203 & -0.014 & 0.191 \\
\hline & & PM 2.5 & -0.233 & -0.137 & 0.078 \\
\hline \multirow{2}{*}{\multicolumn{2}{|c|}{ Overall }} & PM 10 & 0.062 & -0.219 & 0.359 \\
\hline & & PM 2.5 & 0.173 & $\begin{array}{c}-0.344 \\
\end{array}$ & 0.403 \\
\hline
\end{tabular}

Table 4. Correlation coefficients of 5 PM Sensors for PM 10 and PM 2.5

The obtained correlation coefficients were then used to indicate the direction and strength of the correlation. Considering the limitations of the correlation analysis, it is fully acknowledged that mathematical correlation can also be established between two completely unrelated variables (spurious correlation) and the results may not be statistically significant (depending on the size of the sample). The results of the correlation were tested for their significance at 0.05 level for two-tailed test. Test statistics were obtained using the critical values, and for varied number of samples in this study. The formulated hypotheses were null and alternative hypotheses, where null hypothesis was formulated that correlation coefficient was being zero, and for alternative hypothesis, the correlation coefficient being a value other than zero.

\subsubsection{Results of correlation}

\section{a. PM versus Temperature}

The hourly average values of temperatures were negatively correlated with hourly average PM values. The strength of the correlation is moderate to high with maximum negative correlation of -0.77 . The interpretation of correlation indicates that lower magnitudes of PM with higher temperatures and vice versa. The results support the established findings of temperature correlation with PM. Many studies report the effect of high temperature in the effective PM dispersal, resulting in lower PM values.

\section{b. PM versus Humidity}

The hourly average values of humidity were positively correlated with hourly average PM values. The strength of the correlation is moderate to high with maximum positive correlation of +0.73 . The interpretation of correlation indicates that higher magnitudes of PM with higher humidity values. The study of the correlation of humidity is unrelated to the rainfall for this study, as rainfall is a better indicator for PM concentration values. Many research studies show that rainfall lowers the PM concentration, through the binding and washing effect of PM dust with heavy rainfall. Humidity may be a function of rainfall, or local climate, the results of the correlation doesn't support that high values of humidity had lowering effect on PM dust. Thus, this meteorological parameter of humidity failed to support the established fact.

\section{c. PM versus Atmospheric Pressure}

A very weak positive correlation was observed with PM versus atmospheric pressure with largest correlation factor of +0.31 . A few sporadic negative correlations were also found. Also, atmospheric pressure affects the wind speed and wind direction and the effect could easily be captured in the correlation of PM concentration with wind speed and wind direction respectively. Thus, the effect of atmospheric pressure on PM concentration values could be deemed completely uncorrelated.

\section{d. PM versus Wind speed}

A moderate negative correlation was observed with meteorological parameter, wind speed with respect to PM concentration. The largest negative correlation was found to be 0.61 . Thus, higher wind speeds were observed to have negative effect on the PM concentration recorded by the PM sensors. This may well be in accordance to the literature review, since the dispersal of PM dust particles could be deemed as a function of wind speed.

\section{e. PM versus Wind direction}

Positive correlation is found with meteorological parameter, 'wind direction' with respect to PM concentration. The largest positive correlation was found to be +0.75 . All five sensors were placed on the facade of the Building 2 HFT, Stuttgart facing the Schlossstrasse. The orientation of the sensors is 1540 , therefore, any "wind direction' data from is 640 to 2440 should affect the PM concentration due to dispersal effect. However, PM 
concentration is known to have negative correlation with wind speed greater than $1 \mathrm{~m} / \mathrm{s}$. Therefore, the PM concentration is likely to affect with higher wind speed and wind direction which lie in the range of 640 to 2440 degrees respectively. Although, wind tunnel effect, micro-climate effect, etc. on PM concentration are needed to be researched for establishing the relationship with wind direction, they were assumed to be static for the purposes of the study.

All the above results were tested at 0.05 level of significance for two tailed test. The alternative hypotheses were accepted for all cases.

\subsection{Determination of the peak concentration periods of PM 10 and PM 2.5}

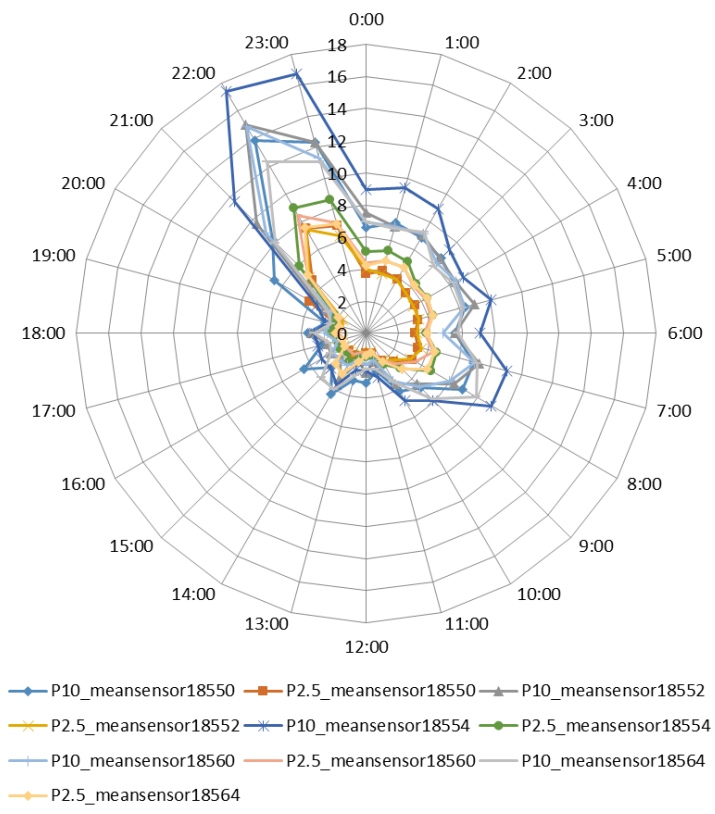

Figure 7. PM concentration for all study sensor for a typical day

When the sensor recordings of PM concentration were analyzed for all sensors to study the pattern, it is found that for a typical day, PM concentration showed peaks between 2200 to 2300 hours, similar peaks were also observed from 0700 to 0800 hours (Fig.5). For the rest of the day, the PM concentration did not show abrupt spikes. However, marginal differences were observed for all five sensors in their recordings for the same size, PM 10 or PM 2.5 at vertical and horizontal placement, when hourly averages were calculated. However, no differences were observed in pattern of the peak periods concentration for both sensors.

\subsubsection{Regression Analysis}

The correlation provided the direction and the strength of the relationship or association between two variables. Although, it is always linear in nature, there is no difference between dependent and independent variables. In order to study the dependency of one variable on the other independent variables, the regression analysis was conducted. Multiple regression relationship between PM 10 as well as PM 2.5 with meteorological parameters were developed. The local area dynamics of air pollution was determined by meteorological factors, e.g., ambient temperature, humidity, air pressure, wind speed, wind direction and by mixing heights respectively.

These factors play an important role in dispersion of air pollutants. For the purposes of this study, PM concentration values were assumed to be dependent on the meteorological factors.

A total of 5 sensors measuring both PM 10 and PM 2.5 concentrations were used for regression analysis. After developing the understanding of regression with individual sensor concentration values, mean concentration values of PM 10 and PM 2.5 concentration were later used to explain the variation using coefficient of determination $\mathrm{R} 2$. In regression analysis, for $\mathrm{R} 2=1$, there would be no variation remaining that is unexplained by the independent variables used in regression model. When $\mathrm{R} 2$ $=0$, the independent variable used would not explain any of the observed variation in the dependent variable. Since the range of $\mathrm{R} 2$ lies between 0 and 1, the range of $\mathrm{R} 2$ values can be used to indicate the effectiveness of the variables used and the accuracy of the regression model. A backward elimination regression analysis was conducted to find out the desired $\mathrm{R} 2$ for all $\mathrm{p}$ values greater than 0.05 .

Results of Regression Analysis

- Temperature, Pressure and Wind speed had negative coefficients, indicating the negative relationships with PM concentration. The humidity and wind direction had positive coefficients.

\begin{tabular}{|c|c|c|c|c|c|c|c|c|c|}
\hline $\begin{array}{c}\text { Sensor } \\
\text { Num. } \\
185 x x\end{array}$ & PM & Inter. & Temp. & Humid. & Press. & $\begin{array}{c}\text { Wind } \\
\text { speed }\end{array}$ & $\begin{array}{c}\text { Wind } \\
\text { dir. }\end{array}$ & $\begin{array}{c}\mathrm{P} \\
\text { elim. }\end{array}$ & $\mathrm{R}^{2}$ \\
\hline \multirow{2}{*}{50} & 10 & 190.46 & -0.11 & 0.04 & -0.18 & -0.05 & 0.32 & $\uparrow$ & 0.32 \\
\cline { 2 - 10 } & 2.5 & 89.72 & -0.13 & 0 & -0.08 & -0.07 & 0.13 & $\uparrow$ & 0.46 \\
\hline \multirow{2}{*}{52} & 10 & 160.16 & -0.13 & 0.05 & -0.15 & 0.2 & 0.25 & $\downarrow$ & 0.26 \\
\cline { 2 - 10 } & 2.5 & 74.14 & -0.05 & 0.03 & -0.07 & 0 & 0.15 & $\downarrow$ & 0.37 \\
\hline \multirow{2}{*}{54} & 10 & 197.62 & -0.07 & 0.1 & -0.19 & 0 & 0.37 & $\downarrow$ & 0.38 \\
\cline { 2 - 10 } & 2.5 & 99.73 & -0.13 & 0.03 & -0.09 & -0.1 & 0.18 & $\uparrow$ & 0.55 \\
\hline \multirow{2}{*}{60} & 10 & 119.45 & -0.03 & 0.08 & -0.12 & -0.05 & 0.33 & $\downarrow$ & 0.43 \\
\cline { 2 - 10 } & 2.5 & 76.46 & -0.1 & 0.03 & -0.07 & -0.07 & 0.18 & $\uparrow$ & 0.57 \\
\hline \multirow{2}{*}{64} & 10 & 138.54 & 0.12 & 0.11 & -0.14 & 0.12 & 0.67 & $\downarrow$ & 0.44 \\
\cline { 2 - 10 } & 2.5 & 31.26 & 0.08 & 0.07 & -0.03 & -0.01 & 0.4 & $\uparrow$ & 0.55 \\
\hline \multirow{2}{*}{ Mean } & 10 & 89.43 & -0.21 & 0.02 & -0.08 & 0.04 & 0.29 & $\downarrow$ & 0.35 \\
\cline { 2 - 10 } & 2.5 & 37.13 & -0.15 & 0 & -0.03 & -0.04 & 0.15 & $\uparrow$ & 0.5 \\
\hline
\end{tabular}

Table 5. ,Coefficients of determination“ of 5 sensors for PM 10 and PM 2.5

- The R2 values ranged from 0.26 to 0.57 indicating a weak to small variations in the dependent variable (PM concentration) w.r.t. independent variables.

- The backward elimination methods of step-wise regression yield both negative and positive effect on the coefficient of determination $\mathrm{R} 2$. In any combination of independent variables, the $\mathrm{R} 2$ reached a maximum of 0.57 . The backward elimination methods of step-wise regression yield both negative and positive effect on the coefficient of determination R2. In any combination of independent variables, the $\mathrm{R} 2$ reached a maximum of 0.57 . 
- A typical model with adjusted R2 is given below"

$-\quad[\mathrm{PM} 2.5]=76.46-0.10 \times[\mathrm{t}]-0.03 \times[\mathrm{h}]-0.07 \times[\mathrm{ap}]-$ $0.07 \times[\mathrm{ws}]+0.18 \times[\mathrm{wd}]$,

- $[\mathrm{PM} 2.5 / 10]$ Concentration of PM 10/2.5 in $\mu \mathrm{g} / \mathrm{m} 3$,[TEMP] Temperature in ${ }^{\circ} \mathrm{C},[\mathrm{RH}]$ Relative Humidity in \%,[AP] Air Pressure in mbar,[WS] Wind speed in $\mathrm{m} / \mathrm{s}$, [WD] Wind direction in radians

- In all cases, when PM 2.5 data were used, the R2 yield higher values when compared with PM 10 for the same locations, indicating better fit for chosen independent variables

\section{CONCLUSIONS \& RECOMMENDATIONS}

There is no significant different for air quality measurements (PM 2.5 and PM 10) in different horizontal distance and in the range of 6 meters different height. We recommend to perform the further experiment to measure the correlation of height difference parameters in PM measurements, such as using larger height different more than 10 meters.

The RMSE of PM 2.5 and PM 10 are $5.136 \square \mathrm{g} / \mathrm{m} 3$ and 4.269 $\square \mathrm{g} / \mathrm{m} 3$ comparing to high accuracy PM sensor in Stuttgart Bad Cannstatt. When use high accuracy sensor (LUBW sensor) should be better if we can access the original or the raw data of both PM 2.5 and PM 10. Because in the experiment we only get the data from the website that show the integer value in the display or the diagram.

The PM concentration data is needed to processed based on the days of the week, month. The data could be further refined based on the traffic scheduling, morning, afternoon and evening peak periods (periods of observations). This would give a better estimation of the PM relationship with meteorological factors. Father data collection is needed to study effects of those factors on PM concentration.

The data of variables where higher PM concentration is observed, demand a large data sets to explain differences. Since the PM concentration is a function of household, industrial and commercial activities, the worst case scenarios using combination of activities could be used to predict PM concentration values.

Accuracy of Low-cost PM sensors is questionable, as PM concentration values when compared with the high quality sensors, were largely underestimated.

High and lows in PM concentration were observed in multiple cases, however, without reasonable explanation or known changes in the boundary conditions. There is need to develop reliable low-quality PM sensors.

\section{ACKNOWLEDGEMENT}

This publication was produced in the project „Neue Möglichkeiten der Datenerhebung, -analyse und Auswirkungsabschätzung im Wasser-Energie Nexus - NeMDa“, which is part of the Baden-Württemberg-STIPENDIUM for University Students - BWS plus, a programme of the BadenWürttemberg Stiftung. The authors would like to thank the Baden-Württemberg Stiftung for its support.

\section{REFERENCES}

Fine dust sensor construction manual - luftdaten.info measure air quality yourself. (n.d.). Retrieved July 5, 2019, from https://luftdaten.info/en/construction-manual/\#sub_menu1.

Genikomsakis, Konstantinos N., et al. "Development and OnField Testing of Low-Cost Portable System for Monitoring PM2.5 Concentrations." Sensors, vol. 18, no. 4, Jan. 2018, p. 1056., doi:10.3390/s18041056.

Goodsite, Michael Evan, and Ole Hertel. "Urban Air Quality Urban Air Quality : Sources Urban Air Quality Sources and Concentrations Urban Air Quality Concentrations." Encyclopedia of Sustainability Science and Technology, 2012, pp. 11291-11311., doi:10.1007/978-1-4419-0851-3_321.

Johnson, Karoline K., et al. "Field Test of Several Low-Cost Particulate Matter Sensors in High and Low Concentration Urban Environments." Aerosol and Air Quality Research, vol. 18, no. 3, 2018, pp. 565-578., doi:10.4209/aaqr.2017.10.0418.

Liu, Hai-Ying, et al. "Performance Assessment of a Low-Cost PM2.5 Sensor for a near Four-Month Period in Oslo, Norway." Atmosphere, vol. 10, no. 2, 2019, p. 41., doi:10.3390/atmos10020041.

Mukherjee, Anondo, et al. "Assessing the Utility of Low-Cost Particulate Matter Sensors over a 12-Week Period in the Cuyama Valley of California.” Sensors, vol. 17, no. 8, May 2017, p. 1805. doi:10.3390/s17081805.

Schneider, Philipp, et al. "Mapping Urban Air Quality in near Real-Time Using Observations from Low-Cost Sensors and Model Information.” Environment International, vol. 106, 2017, pp. 234-247., doi:10.1016/j.envint.2017.05.005.

Spinelle, Laurent, et al. "Review of Portable and Low-Cost Sensors for the Ambient Air Monitoring of Benzene and Other Volatile Organic Compounds.” Sensors, vol. 17, no. 7, 2017, p. 1520., doi:10.3390/s17071520.

Zheng, Tongshu, et al. "Field Evaluation of Low-Cost Particulate Matter Sensors in High Andlow Concentration Environments." Atmospheric Measurement Techniques Discussions, 2018, pp. 1-40., doi:10.5194/amt-2018-111. 